\title{
One-pot $N$-alkylation of primary amines to secondary amines by gold clusters supported on porous coordination polymers
}

\author{
Tamao Ishida, ${ }^{1,3,{ }^{*}}$ Noriko Kawakita, ${ }^{1,3}$ Tomoki Akita ${ }^{2,3}$ and Masatake Haruta ${ }^{1,3}$ \\ www.goldbulletin.org
}

\begin{abstract}
Gold clusters and nanoparticles were deposited on the three kinds of porous coordination polymers (PCPs), MOF-5, CPL-2, and AI-MIL53 by the solid grinding method. The size of Au particles depended on the kinds of PCPs and increased in the order of Al-MIL53 < CPL-2 < MOF-5. The mean diameter of $\mathrm{Au}$ particles supported on Al-MIL53 was estimated to be $1.6 \mathrm{~nm}$ by HAADFSTEM. Such small Au clusters on AI-MIL53 can catalyze one-pot synthesis of secondary amines from primary amines by sequential oxidation/hydrogenation owing to the remarkable improvement of hydrogenation efficiency of imine. Gold clusters deposited on AI-MIL53 can also promote $\mathrm{N}$-alkylation of amine with alcohol to form a secondary amine under $\mathrm{N}_{2}$ atmosphere without using $\mathrm{O}_{2}$ and $\mathrm{H}_{2}$.
\end{abstract}

\footnotetext{
Department of Applied Chemistry, Graduate School of Urban Environmental Sciences, Tokyo Metropolitan University, 1-1,Minami-osawa, Hachioji, Tokyo 192-0397, Japan 2 Research Institute for Ubiquitous Energy Devices, National Institute of Advanced Industrial Science and Technology (AIST), 1-8-31, Midorigaoka, Ikeda, Osaka 563-8577, Japan Japan Science and Technology Agency (JST), CREST, 4-1-8 Hon-cho, Kawaguchi, Saitama, 322-0012, Japan

*Corresponding author: ishida-tamao@center.tmu.ac.jp
}

\section{Introduction}

Gold exhibits unique catalytic properties for a number of vapor and liquid phase reactions when it is deposited as nanoparticles (NPS) smaller than 10 $\mathrm{nm}$ on base metal oxides (1). Gold NPs supported on or stabilized by organic polymers, on the other hand, have recently been prepared and have shown that they are catalytically active for liquid phase oxidations (2-6). Since the size sensitivity of the catalysis by Au NPs is stronger over inert supports such as carbons and organic polymers than over metal oxides, it often happens that the critical diameter of $\mathrm{Au}$ particles appears at around $2 \mathrm{~nm}$, below which catalytic capability dramatically changes.

Porous coordination polymers (PCPs) with highly ordered nanometer-sized porous structures have been attracting growing interests as supports for metal clusters smaller than $2 \mathrm{~nm}$ in diameter (7-11). It has been reported that $\mathrm{Pd}(7,8), \mathrm{Cu}(7), \mathrm{Ru}(9)$ clusters in the range of 1-3 nm could be deposited on or in PCPs by chemical vapor deposition (CVD) whereas Au clusters with diameters of smaller than $2 \mathrm{~nm}$ had been hardly obtained by CVD because of the weak interactions of Au with PCP frameworks (7). Recently, we have developed a new deposition technique that enables the deposition of $\mathrm{Au}$ as clusters on PCPs and have found that the supported Au clusters and Au NPs smaller than 5 $\mathrm{nm}$ are catalytically active for the aerobic oxidation of alcohols (10). However, the kinds of PCP support strongly affected the catalytic activity more significantly than the size of Au particles. We have explored new reactions by using a variety of Au/PCPs as catalysts and have found that $\mathrm{Au}$ clusters on PCPs are catalytically more active than larger Au NPs on PCPs in the sequential one-pot $\mathrm{N}$-alkylations of primary amines involving (i) oxidation of amine (Scheme 1a) or alcohol (Scheme 1b), (ii) imine formation, and (iii) hydrogenation of imine. 


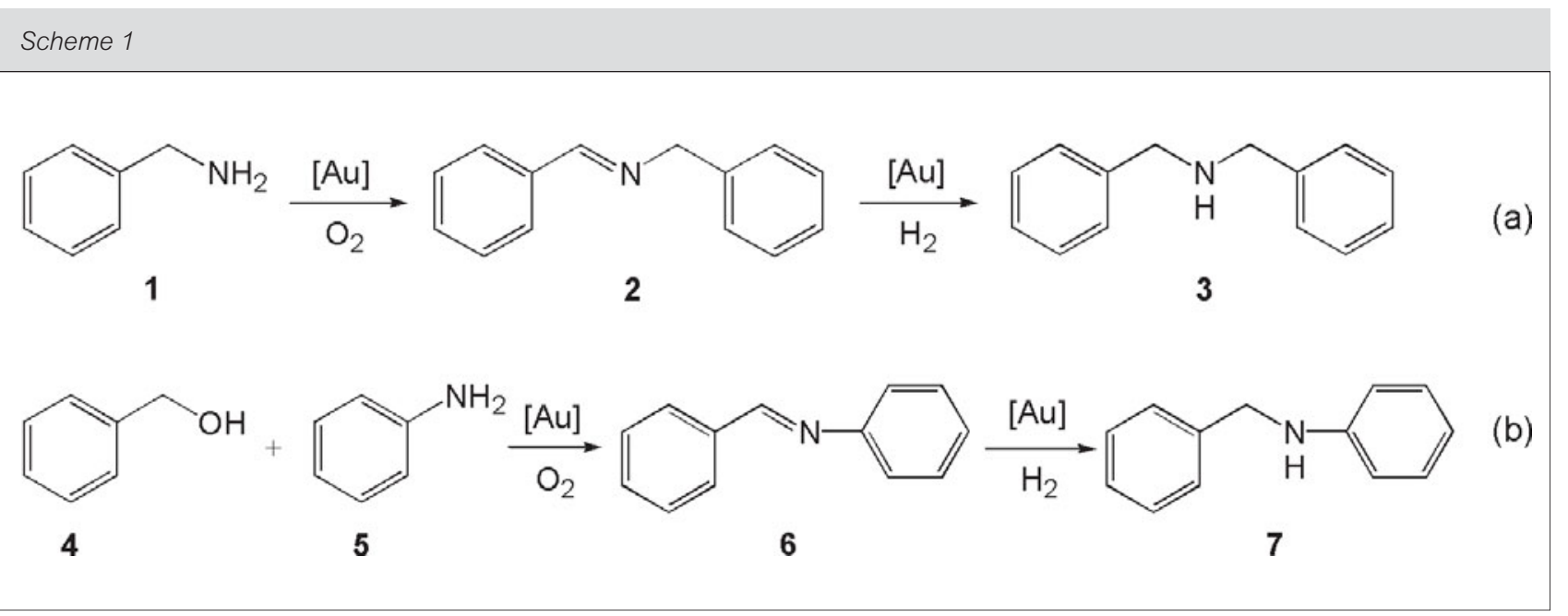

One-pot synthesis of symmetric secondary amine (a) and of asymmetric secondary amine (b)

During the course of our investigation, the sequential one-pot synthesis of secondary amine in Scheme 1a by $\mathrm{Au} / \mathrm{TiO}_{2}$ and $\mathrm{Au} / \mathrm{C}$ was demonstrated by Grirrane et al. (12) and the one-pot synthesis of imine in Scheme $1 \mathrm{~b}$ by Au/hydroxyapatite was reported by Sun et al (13). However, the effect of the size of Au NPs on the reactions was studied only for the first oxidation step by using Au NPs larger than $3.5 \mathrm{~nm}$. In addition, catalytic performance of polymer supported Au catalysts for hydrogenation reactions has not yet been explored. Herein, we demonstrate that one-pot $N$-alkylations can be performed by using PCP-supported Au clusters owing to the markedly improved catalytic activity for hydrogenation. It has also been found that $\mathrm{Au}$ clusters catalyzed the one-pot $N$-alkylation of amine with alcohol even under inert atmosphere.

\section{Experimental section}

\subsection{Materials}

Porous coordination polymers, Al-MIL53 $\left([\mathrm{Al}(\mathrm{OH})(\mathrm{bdc})]_{n}, \mathrm{bdc}=\right.$ benzene-1,4-dicarboxylate $)$ (14) and MOF-5 $\left(\left[\mathrm{Zn}_{4} \mathrm{O}(\mathrm{bdc})_{3}\right]_{n}\right)(15)$ were supplied by BASF. CPL-2 $\left(\left[\mathrm{Cu}_{2}(\text { pzdc })_{2}(\text { bpy })\right]_{n}\right.$, pzdc = pyrazine2,3-dicarboxylate, bpy $=4,4$ '-bipyridine) was prepared according to the literature (16). Dimethyl acetylacetonatogold(III) complex ( $\mathrm{Me}_{2} \mathrm{Au}(\mathrm{acac})$ ) was purchased from Tri Chemical Laboratories Inc. and was used without further purification. Benzylamine, benzylalcohol, aniline, N-benzylidenebenzylamine, $\mathrm{N}$-benzylideneaniline, anisole, toluene (dehydrated), diethyl ether, $\mathrm{Cs}_{2} \mathrm{CO}_{3}$, and 2-propanol, all reagent grades, were purchased and used as received.

\subsection{Instruments}

Gold clusters and NPs were observed with a highangle annular dark-field scanning transmission electron microscopy (HAADF-STEM) using a JEOL JEM-3000F operating at $300 \mathrm{kV}$. Particle size distributions were taken from more than 200 particles. Quantitative analysis was performed by a gas chromatography (SHIMADZU GC-14B with a G-Column G-205, 1.2 mm i.d., 40 m, Chemicals Evaluation and Research Institute Japan) using anisole as an internal standard. Qualitative analysis was performed with a GC-MS (SHIMADZU PARVUM and GC-2010 with a Shinwa Chemical ULBON HR-1 capillary column, $0.25 \mathrm{~mm}$ i.d., $30 \mathrm{~m}$ ).

\subsection{Catalyst preparation}

Gold on PCPs were prepared by the solid grinding method (10). Support (300 mg) and $\mathrm{Me}_{2} \mathrm{Au}(\mathrm{acac})$ (10 mg, 2 wt\% of Au loading) were ground in an agate mortar in air at room temperature for $20 \mathrm{~min}$. The gold(III) precursor adsorbed on the support was reduced in a stream of $10 \mathrm{vol} \% \mathrm{H}_{2}$ in $\mathrm{N}_{2}$ at a flow rate of $50 \mathrm{~mL} / \mathrm{min}$ at $120^{\circ} \mathrm{C}$ for $2 \mathrm{~h}$ to yield Au/PCP. Gold on $\mathrm{TiO}_{2}$ (1 wt\% of theoretical Au loading) was prepared by the deposition-precipitation method according to the procedures described in the literature (17).

\subsection{Catalytic tests}

2.4.1 One-pot synthesis of dibenzylamine from benzylamine

An autoclave was charged with a magnetic stirring bar, benzylamine $(110 \mu \mathrm{L}, 1.0 \mathrm{mmol})$, Au catalyst (Au $1 \mathrm{~mol} \%)$, and toluene $(3.0 \mathrm{~mL})$. Oxygen was introduced into the autoclave until the pressure reached $0.5 \mathrm{MPa}$. The reaction mixture was stirred 

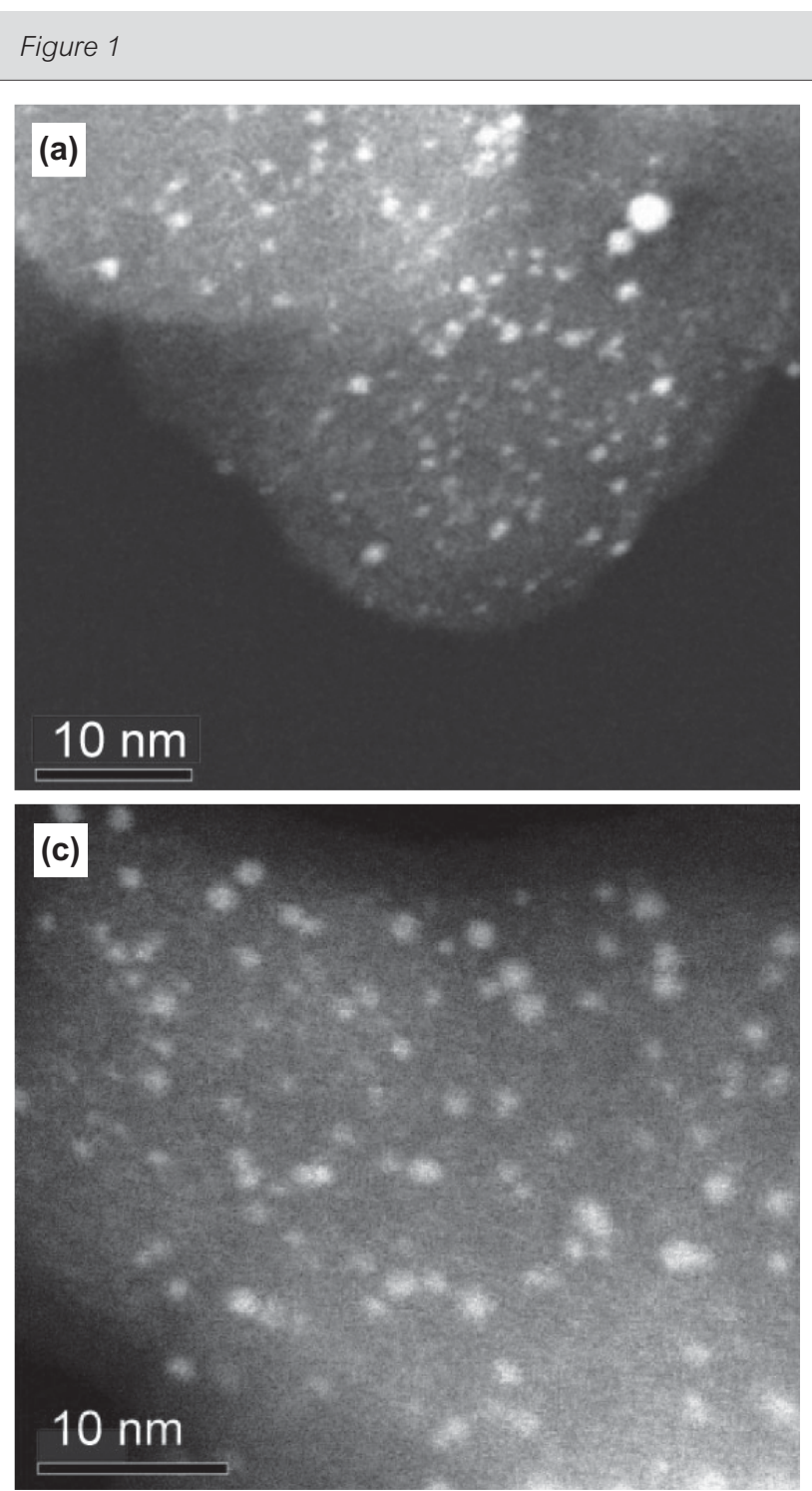

(b)

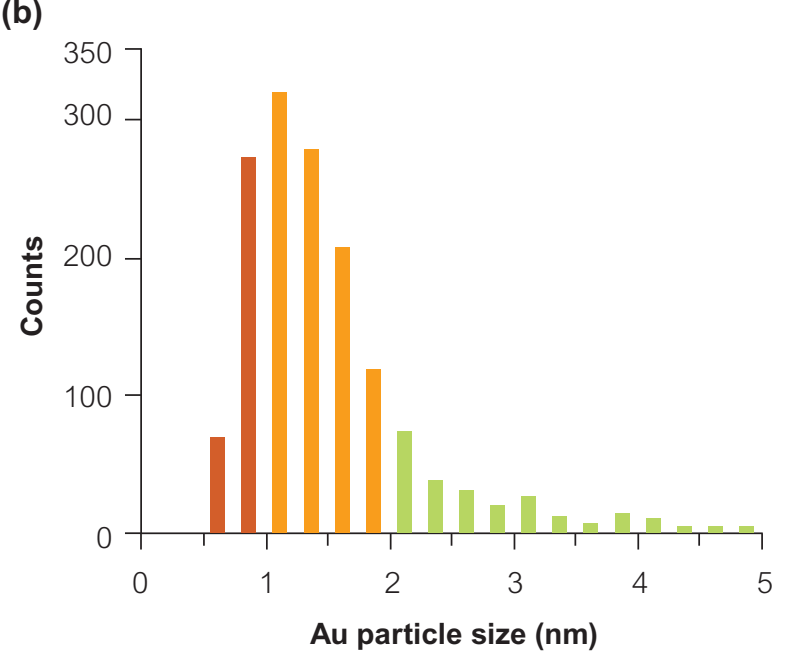

(d)
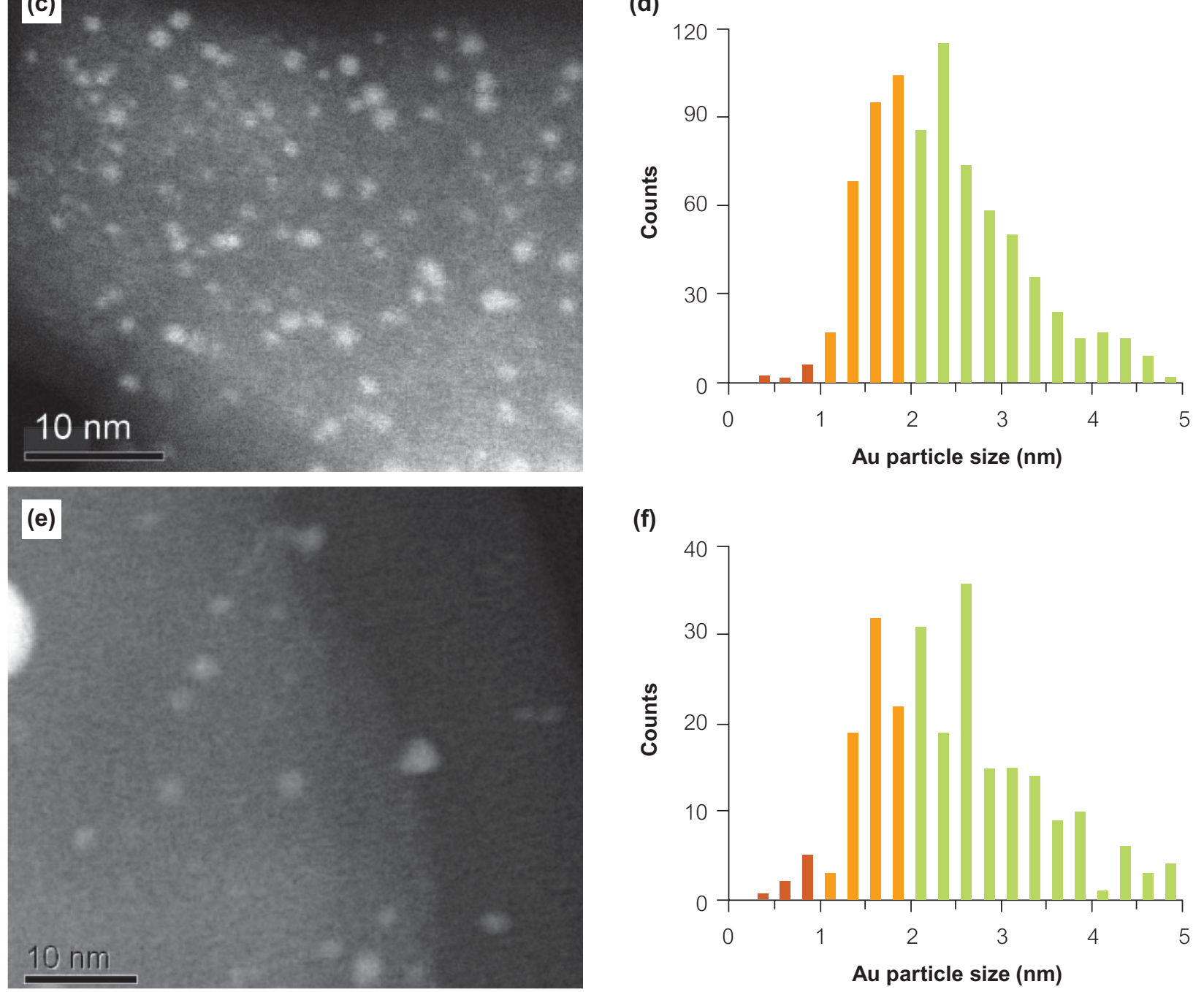

(f)

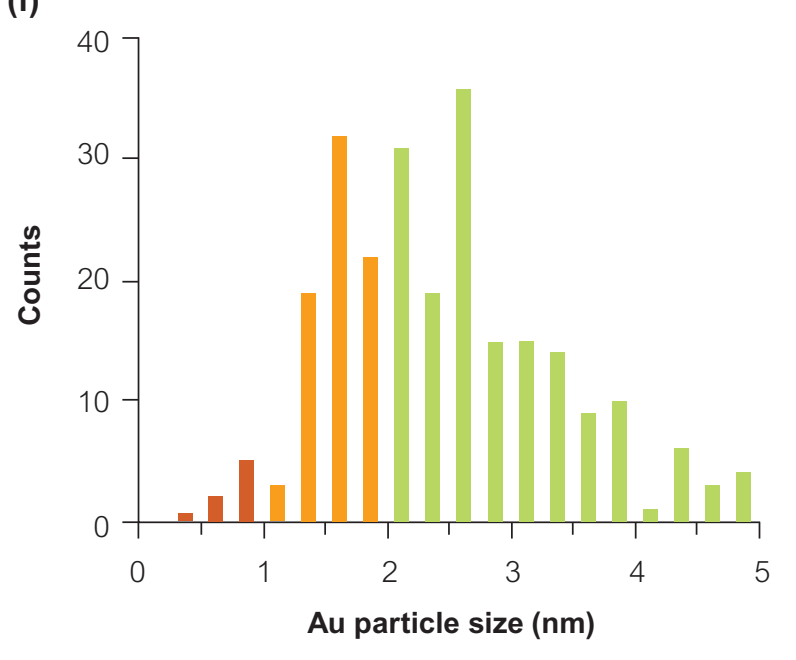

HAADF-STEM images and the size distributions of 2 wt\% AulAI-MIL53 (a, b), 2 wt\% Au/CPL-2 (c, d), and 2 wt\% Au/MOF-5 (e, f) 
at $100^{\circ} \mathrm{C}$ for $22 \mathrm{~h}$. After the oxidation, $\mathrm{O}_{2}$ was removed, purged by $\mathrm{H}_{2}$ several times, and then $\mathrm{H}_{2}$ was introduced until the pressure reached $0.5 \mathrm{MPa}$. The reaction mixture was again stirred at $100^{\circ} \mathrm{C}$ for $22 \mathrm{~h}$. The reaction mixture was extracted with $\mathrm{Et}_{2} \mathrm{O}$, filtered, and analyzed by GC-MS and GC using anisole as an internal standard.

\subsubsection{One-pot synthesis of N-phenylbenzylamine from aniline with benzylalcohol}

An autoclave was charged with a magnetic stirring bar, benzylalcohol (52 $\mu \mathrm{L}, 0.5 \mathrm{mmol}$ ), aniline (46 $\mu \mathrm{L}, 0.5 \mathrm{mmol}$ ), Au catalyst (Au $1 \mathrm{~mol} \%$ ), and toluene $(3.0 \mathrm{~mL})$. The following procedures were the same as in 2.4.1 except for the reaction temperature at $120^{\circ} \mathrm{C}$.

\subsubsection{One-pot N-alkylation of aniline with benzylalcohol under $\mathrm{N}_{2}$ atmosphere}

A glass reactor was charged with a magnetic stirring bar, benzylalcohol (52 $\mu \mathrm{L}, 0.5 \mathrm{mmol})$, aniline $(46 \mu \mathrm{L}$, $0.5 \mathrm{mmol}$ ), Au catalyst (74 mg, Au $1.5 \mathrm{~mol} \%), \mathrm{Cs}_{2} \mathrm{CO}_{3}$ (168 mg, $0.5 \mathrm{mmol})$, and toluene $(3.0 \mathrm{~mL})$. Then the mixture was stirred under $\mathrm{N}_{2}$ atmosphere at $110^{\circ} \mathrm{C}$ for $22 \mathrm{~h}$. The reaction mixture was washed with $\mathrm{H}_{2} \mathrm{O}$, extracted with $\mathrm{Et}_{2} \mathrm{O}$, dried over $\mathrm{Na}_{2} \mathrm{SO}_{4}$, filtered, and analyzed by GC-MS and GC using anisole as an internal standard.

\subsubsection{Hydrogen transfer reaction of N-benzylideneaniline with 2-propanol}

A glass reactor was charged with a magnetic stirring bar, N-benzylideneaniline (91 mg, $0.5 \mathrm{mmol}$ ), 2propanol (0.38 mL, $5 \mathrm{mmol}), 2$ wt\% Au/Al-MIL53 (99 $\mathrm{mg}$, Au $2 \mathrm{~mol} \%), \mathrm{Cs}_{2} \mathrm{CO}_{3}$ (163 mg, $0.5 \mathrm{mmol}$ ), and toluene $(2.0 \mathrm{~mL})$. The following procedures were the same as in 2.4.3 except for the reaction temperature at $120^{\circ} \mathrm{C}$ and time for $24 \mathrm{~h}$.

\section{Results}

\subsection{Deposition of gold clusters onto porous coordination polymers}

Figure 1 shows the HAADF-STEM images and the size distributions of Au particles deposited on PCPs. All the three kinds of PCPs could support Au NPs smaller than $5 \mathrm{~nm}$. In particular, over Al-MIL53, 80\% of Au particles could be deposited as clusters with diameters below $2 \mathrm{~nm}$. The mean diameter of $\mathrm{Au}$ particles could be minimized to $1.6 \pm 1.0 \mathrm{~nm}$ (Figure 1a, b, and Table 1), whereas the mean diameters of Au particles in Au/CPL-2 and Au/MOF-5 were larger than that in Au/Al-MIL53 and estimated to be $2.4 \pm 1.0$ and $3.3 \pm 2.3 \mathrm{~nm}$, respectively (Figure $1 \mathrm{c}-\mathrm{f}$ and Table 1).

\subsection{One-pot synthesis of symmetric secondary amine from primary amine}

Table 1 summarizes the experimental results of onepot synthesis of dibenzylamine (3) from benzylamine (1) by sequential oxidation/hydrogenation via the formation of $N$-benzylidenebenzylamine (2) (18) (Scheme 1a). In terms of yields of $\mathbf{2}$ and $\mathbf{3}$, the catalytic activity of Au/PCPs for the first oxidation step increased with a decrease in the mean diameter of Au particles but only slightly. In contrast, Au/Al-MIL53 exhibited much higher catalytic activity (entry 1) than Au/CPL-2 (entry 3) and Au/ MOF-5 (entry 4) for the second hydrogenation step, indicating that hydrogenation is more sensitive to the diameter of $\mathrm{Au}$ particles than oxidation. An increase in reaction temperature and the amount of Au catalyst improved the yield of 3 up to $91 \%$ (entry 2). Grirrane et al. reported that $\mathrm{Au} / \mathrm{TiO}_{2}$ catalyzed one-pot synthesis of 3 at $100^{\circ} \mathrm{C}$ according to Scheme 1a (12), however, Au/ $\mathrm{TiO}_{2}$ catalysts prepared by us did not produce 3 under our reaction conditions (entry 5).

Table 1: One-pot synthesis of dibenzylamine (3)

\begin{tabular}{|cccccc|}
\hline Entry & Catalyst & Au size $(\mathbf{n m}) \mathbf{b}$ & Conv. (\%) & Yield 2 (\%) & Yield 3 (\%) $^{\mathbf{c}}$ \\
\hline 1 & Au/Al-MIL53 & $1.6 \pm 1.0$ & 67 & 0 & 51 \\
$2^{\mathrm{d}}$ & Au/Al-MIL53 & $1.6 \pm 1.0$ & $>99$ & 0 & 91 \\
3 & Au/CPL-2 & $2.4 \pm 1.0$ & $81^{\mathrm{e}}$ & 38 & 1 \\
4 & $\mathrm{Au} / \mathrm{MOF}-5$ & $3.3 \pm 2.3$ & $90^{\mathrm{e}}$ & 22 & 2 \\
5 & $\mathrm{Au} / \mathrm{TiO}$ & 60 & 43 & trace \\
\hline
\end{tabular}

${ }^{a}$ Reaction conditions: benzylamine (1.0 mmol), Au catalyst (Au $1 \mathrm{~mol} \%$ ), toluene $(3.0 \mathrm{~mL}), 100^{\circ} \mathrm{C} . \mathrm{O}_{2} 0.5 \mathrm{MPa}$ for $22 \mathrm{~h}$ and then $\mathrm{H}_{2} 0.5$ MPa for $22 \mathrm{~h}$

${ }^{b}$ Observed by HAADF-STEM. ${ }^{\circ}$ GC conversions and yields after the hydrogenation obtained by using anisole as an internal standard.

a The reaction was carried out at $120^{\circ} \mathrm{C}$ over $2 \mathrm{~mol} \%$ of Au. ${ }^{e}$ High conversions and low yields were due to poor mass balances.

${ }^{\dagger}$ Observed by TEM 


\subsection{One-pot synthesis of asymmetric secondary amine by $\mathrm{N}$-alkylation of alcohol with amine}

We have also investigated the one-pot synthesis of an asymmetric secondary amine, $N$-phenylbenzylamine (7), from benzylalcohol (4) with aniline (5) via the formation of $N$-benzylideneaniline (6) (Scheme $1 \mathrm{~b}$ and Table 2). Although all Au/PCP catalysts were selective to benzylalcohol oxidation to produce benzaldehyde, leading to the formation of 6 (entry 1-3), only Au/AI-MIL53 could promote the hydrogenation to give 7 (entry 1). Gold on $\mathrm{TiO}_{2}$ showed lower selectivity to 7 due to the competitive oxidation of $\mathbf{5}$ to form azobenzene (entry 4) (19).

It is worth noting that Au clusters supported on AlMIL53 could promote the one-pot $N$-alkylation of $\mathbf{4}$ with $\mathbf{5}$ under inert atmosphere without $\mathrm{O}_{2}$ and $\mathrm{H}_{2}$ to produce 7 in the co-presence of base (entry 5), whereas Au NPs on CPL-2 and on MOF-5 could not (entry 7,8 ). It can be assumed that hydrogen atoms generated by the dehydrogenation of $\mathbf{4}$ are used for the hydrogenation of $\mathbf{6}$ to give 7. Gold on $\mathrm{TiO}_{2}$ also gave 7 but substantial amounts of by-products were also formed (entry 9). The modification of reaction conditions (C) improved the selectivity to 7 up to $72 \%$ and $76 \%$ based on 4 and 5, respectively, over Au/Al-MIL53 (entry 6).

\section{Discussion}

\subsection{Hydrogenation efficiency in the one-pot synthesis of dibenzylamine}

In order to evaluate the hydrogenation efficiency of Au/PCPs, the hydrogenation of $\mathbf{2}$ to $\mathbf{3}$ was carried out by using freshly prepared Au catalysts (Table 3). Gold on CPL-2 and Au/MOF-5 produced 3 in yields of only 2 and $25 \%$, respectively (entry 2 and 3 ). In contrast, Au/AI-MIL53 achieved a full conversion of $\mathbf{2}$ (entry 1). Therefore, the low catalytic activity of $\mathrm{Au} / \mathrm{CPL}-2$ and Au/MOF-5 in the one-pot synthesis can

Table 2: One-pot N-alkylation of aniline (5) with benzylalcohol (4) to N-phenylbenzylamine (7)

\begin{tabular}{|c|c|c|c|c|c|c|c|c|c|}
\hline \multirow[t]{2}{*}{ Entry } & \multirow[t]{2}{*}{ Catalyst } & \multirow{2}{*}{$\begin{array}{c}\text { Reaction } \\
\text { conditions }^{a}\end{array}$} & \multirow{2}{*}{$\begin{array}{l}\text { Conv. } 4 \\
(\%)^{b}\end{array}$} & \multirow{2}{*}{$\begin{array}{l}\text { Conv. } 5 \\
(\%)^{\mathrm{b}}\end{array}$} & \multicolumn{5}{|c|}{ Yield(\%) $^{\mathrm{b}}$} \\
\hline & & & & & 6 & 7 & PhCHO & $\mathrm{PhCO}_{2} \mathrm{Bn}$ & Benzanilide \\
\hline 1 & Au/Al-MIL53 & $A$ & 41 & 45 & 21 & 16 & 1 & 0 & 0 \\
\hline 2 & Au/CPL-2 & $A$ & 27 & 49 & 21 & trace & trace & 0 & 0 \\
\hline 3 & Au/MOF-5 & $A$ & 31 & 31 & 27 & trace & trace & 0 & 0 \\
\hline $4^{c}$ & $\mathrm{Au} / \mathrm{TiO}_{2}$ & $A$ & 53 & 90 & 45 & 1 & 1 & trace & 0 \\
\hline 5 & Au/Al-MIL53 & $\mathrm{B}$ & 62 & 42 & 19 & 22 & 6 & 6 & 0 \\
\hline 6 & Au/Al-MIL53 & C & 67 & 63 & 11 & 48 & trace & trace & 0 \\
\hline 7 & Au/CPL-2 & $B$ & 14 & 18 & 12 & 0 & trace & 0 & 0 \\
\hline 8 & Au/MOF-5 & $B$ & 89 & 62 & 62 & trace & 23 & trace & trace \\
\hline 9 & $\mathrm{Au} / \mathrm{TiO}_{2}$ & B & $>99$ & 54 & 22 & 15 & 3 & 12 & 12 \\
\hline
\end{tabular}

a Reaction conditions A: benzylalcohol $(0.5 \mathrm{mmol})$, aniline $(0.5 \mathrm{mmol}), 2$ wt\% AulPCP or $1 \mathrm{wt} \% \mathrm{Au} / \mathrm{TiO}$ ( $\mathrm{Au} 1 \mathrm{~mol} \%)$, toluene (3.0 mL), $120^{\circ} \mathrm{C} . \mathrm{O}_{2} 0.5 \mathrm{MPa}$ for $22 \mathrm{~h}$ and then $\mathrm{H}_{2} 0.5 \mathrm{MPa}$ for $22 \mathrm{~h}$. Reaction conditions B: benzylalcohol (0.5 mmol), aniline (0.5 mmol), Cs $\mathrm{CO}_{3}$ (0.5 mmol), Au catalyst (1.5 mol\%), toluene $(3.0 \mathrm{~mL}), \mathrm{N}_{2} 0.1 \mathrm{MPa}, 110^{\circ} \mathrm{C}$ for $22 \mathrm{~h}$. Reaction conditions C: conditions B but Au catalyst (2 mol\%), toluene (2.0 mL), $\mathrm{N}_{2} 0.1 \mathrm{MPa}, 130^{\circ} \mathrm{C}$ for $48 \mathrm{~h}$.

${ }^{b} \mathrm{GC}$ conversions and yields obtained by using anisole as an internal standard

c Azobenzene was formed as a by-product

Table 3: Hydrogenation of N-benzylidenebenzylamine (2)

\begin{tabular}{|c|c|c|c|c|c|c|}
\hline \multirow[b]{2}{*}{ Entry } & \multirow[b]{2}{*}{ Catalyst } & \multirow[b]{2}{*}{ Conv. $(\%)^{b}$} & \multicolumn{4}{|c|}{ Yield (\%) } \\
\hline & & & 3 & $\mathrm{PhCHO}$ & $\mathrm{PhCH}_{2} \mathrm{OH}$ & $\mathrm{PhCH}_{2} \mathrm{NH}_{2}$ \\
\hline 1 & Au/AI-MIL53 & $>99$ & $>99$ & 0 & 0 & 0 \\
\hline 2 & Au/CPL-2 & 10 & 2 & 5 & 1 & 1 \\
\hline 3 & Au/MOF-5 & 41 & 25 & 7 & 6 & 3 \\
\hline 4 & $\mathrm{Au} / \mathrm{TiO}_{2}$ & $>99$ & $>99$ & 0 & 0 & 0 \\
\hline
\end{tabular}

a Reaction conditions: N-benzylidenebenzylamine (0.5 mmol), Au catalyst (Au $1 \mathrm{~mol} \%$ ), toluene (3.0 mL), $\mathrm{H}_{2} 0.5 \mathrm{MPa}, 100^{\circ} \mathrm{C}$ for $22 \mathrm{~h}$. ${ }^{b}$ GC conversions and yields obtained by using anisole as an internal standard 
be mainly ascribed to intrinsically low hydrogenation efficiency. Bus et al. proposed based on hydrogen chemisorption measurements that hydrogen molecules were dissociated and adsorbed on the corners and the edges of Au particles (20). Thus, higher catalytic activity of Au/Al-MIL53 for hydrogenation could be mainly attributed to an increase in the fraction of Au atoms on the corners and the edges with a decrease in the size of $\mathrm{Au}$,

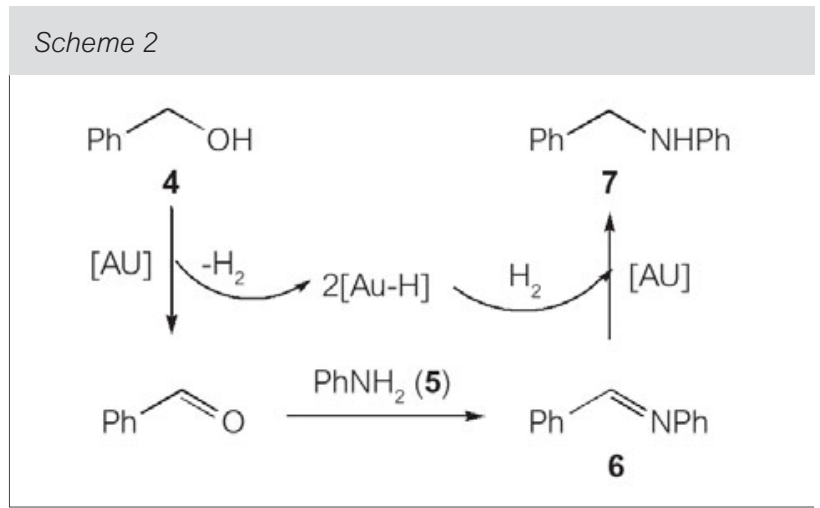

Proposed pathway for the N-Alkylation of $\mathbf{5}$ with $\mathbf{4}$ over Au/MIL-53 under inert atmosphere although support effect cannot be ruled out. Gold on $\mathrm{TiO}_{2}$ afforded 3 quantitatively, thus, the low catalytic activity in the one-pot reaction could be ascribed to the deactivation during oxidation (entry 4).

Although Au/AI-MIL53 showed better catalytic performance for one-pot oxidation/hydrogenation, its recycled use was difficult, failed at this stage of our research due to the aggregation of Au clusters to form larger NPs $(>10 \mathrm{~nm})$ after the one-pot reactions.

\subsection{Reaction pathway for $\mathbf{N}$-alkylation of alcohol with aniline under inert atmosphere}

Abad et al. proposed that $\mathrm{Au}-\mathrm{H}$ species were intermediates formed by the cleavage of the benzylic C-H bond in benzyl alcohol oxidation (21). Hydrogen atoms or hydride species adsorbed on the Au surfaces are considered to be converted with $\mathrm{O}_{2}$ into water to regenerate the Au catalytic sites. This means that $\mathrm{O}_{2}$ works as a hydrogen acceptor. This pathway was also proposed by Fristrup et al. by isotope labeling experiments (22) and was supported by ESR study by Conte et al (23).

\section{Scheme 3}<smiles>CC(C)O</smiles>

6

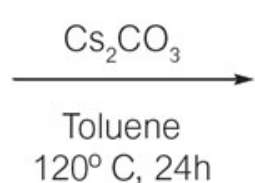

Au/AI-MIL53

$\mathrm{Au} / \mathrm{MOF}-5$<smiles></smiles>

7 yield $0 \%$

Hydrogen transfer reaction of 2-propanol with 6 under $\mathrm{N}_{2}$. Reaction conditions: 6 (0.5 mmol), 2-propanol (5 mmol), 2 wt\% Au cat. (100 $\mathrm{mg}$, Au $2 \mathrm{~mol} \%), \mathrm{Cs}_{2} \mathrm{CO}_{3}(0.5 \mathrm{mmol})$, and toluene $(2.0 \mathrm{~mL}) .120^{\circ} \mathrm{C}$ for $24 \mathrm{~h}$ under $\mathrm{N}_{2}$ atmosphere. Yields were determined by $\mathrm{GC}$

\section{Scheme 4}

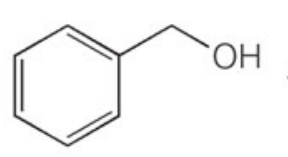

4

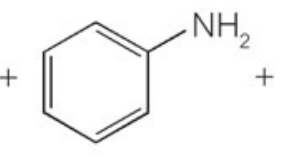

5<smiles>CCC(C)O</smiles>
$130^{\circ} \mathrm{C}, 48 \mathrm{~h}$

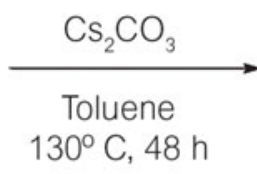<smiles>CNCc1ccccc1</smiles>

7

yield $30 \%$<smiles>CC(=O)c1ccccc1</smiles>

Au/Al-MIL53 selec. 77\% (based on 4), 97\% (based on 5)

$\mathrm{N}$-Alkylation of 5 with $\mathbf{4}$ in the presence of 2-propanol and $\mathrm{Cs}_{2} \mathrm{CO}_{3}$ under $\mathrm{N}_{2}$ atmosphere. Reaction conditions: 4 (0.5 mmol), 5 (0.5 mmol), 2-propanol (3 mmol), $2 \mathrm{wt} \%$ Au cat. (100 mg, Au $2 \mathrm{~mol} \%$ ), $\mathrm{Cs}_{2} \mathrm{CO}_{3}(0.5 \mathrm{mmol})$, and toluene (2.0 $\left.\mathrm{mL}\right) .130{ }^{\circ} \mathrm{C}$ for $48 \mathrm{~h}$ under $\mathrm{N}_{2}$ atmosphere. Yield was determined by GC 
In $\mathrm{N}$-alkylation, $\mathbf{6}$ could act as a hydrogen acceptor with a similar role of $\mathrm{O}_{2}$ in alcohol oxidations. Therefore, it is most likely that Au-catalyzed $\mathrm{N}$-alkylation is composed of three reactions: (i) the dehydrogenation of alcohol to aldehyde with the formation of Au-H species, (ii) the formation of imine from aldehyde with amine, and (iii) the hydrogen transfer from $\mathrm{Au}-\mathrm{H}$ to imine, yielding secondary amine (Scheme 2).

In order to confirm this assumption, the hydrogen transfer reaction from 2-propanol to 6 was studied under $\mathrm{N}_{2}$ atmosphere (Scheme 3). Over Au/AI-MIL53, 2-propanol was dehydrogenated to produce acetone, leading to hydrogenation of $\mathbf{6}$ to $\mathbf{7}$ with a selectivity of $96 \%$. This result excluded the possibility of direct dehydration of $\mathbf{4}$ with $\mathbf{5}$. Recently, Su et al. reported hydrogen transfer reaction of carbonyl and nitro groups into alcohol and amino groups, respectively, over Au/TiO, with 2-propanol as a hydrogen donor (24). Gold NPs supported on carbon showed much lower catalytic activity than $\mathrm{Au} / \mathrm{TiO}_{2}$ in spite of similar size of Au NPs owing to the lack of support effect. In addition, imine is more stable than nitro compounds under hydrogenation conditions (25). It should be noticed again that $N$-alkylation and hydrogen transfer reaction of imine can be performed over Au clusters but not over Au NPs when Au was deposited on PCPs. Although the support effect of Al-MIL53 cannot be fully excluded, the existence of Au clusters smaller than $2 \mathrm{~nm}$ as the majority over the surfaces of PCPs might be an important factor to use $\mathrm{Au}-\mathrm{H}$ species as reducing agents (26).

Finally, N-alkylation of $\mathbf{4}$ with $\mathbf{5}$ over Au/Al-MIL53 was investigated in the presence of excess amount of 2-propanol as a hydrogen donor (Scheme 4). Although the yield of $\mathbf{7}$ decreased, the selectivity was appreciably improved to $77 \%$ and $97 \%$ based on $\mathbf{4}$ and 5, respectively. This result suggested that excess amount of $\mathrm{Au}-\mathrm{H}$, which was supplied from 2-propanol, enhanced the hydrogen transfer efficiency.

\section{Conclusions}

Gold clusters smaller than $2 \mathrm{~nm}$ in diameter supported on AI-MIL53 enabled one-pot synthesis of secondary amines from primary amines by sequential oxidation/hydrogenation. Such Au clusters could also promote the $\mathrm{N}$-alkylation of aniline with benzylalcohol in the co-presence of base without $\mathrm{O}_{2}$ and $\mathrm{H}_{2}$. It was found that the hydrogenation of imine to amine was significantly enhanced when $\mathrm{Au}$ clusters are smaller than $2 \mathrm{~nm}$, leading to high catalytic performance for one-pot, two-steps synthesis of secondary amines. Furthermore, Au clusters on Al-MIL53 could use Au-H species generated by the dehydrogenation of alcohol for the hydrogenation of imine by hydrogen transfer.

\section{Acknowledgement}

We thank Dr. U. Müller and Mr. N. Takenaka of BASF for supplying Al-MIL53 and MOF-5 samples. This work was supported by JST-CREST and a Grant-inAid for Young Scientists (B) (no. 21750160) from the Ministry of Education, Culture, Sports, Science and Technology, Japan.

\section{About the authors}

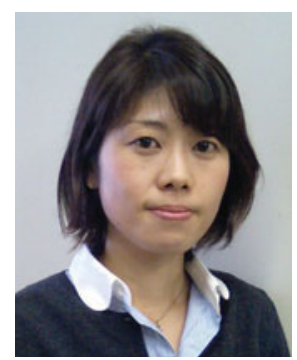

Tamao Ishida received $\mathrm{PhD}$ from Kyoto University in March, 2006. After JSPS post-doctoral fellow at Kyoto University, in August 2006, she joined Prof. Haruta's group of Tokyo Metropolitan University as an assistant professor.

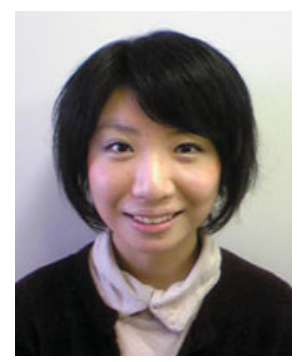

Noriko Kawakita is now a master course student at the Department of Applied Chemistry, Tokyo Metropolitan University, Japan.

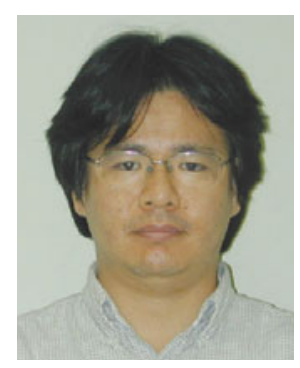

Tomoki Akita received PhD from Osaka University in 1998. After working as a post-doctoral researcher at Osaka National Research Institute (ONRI, currently AIST), he obtained a researcher position at ONRI in 1999. $\mathrm{He}$ is now a senior research scientist at the Research Institute for Ubiquitous Energy Devices, AIST. 


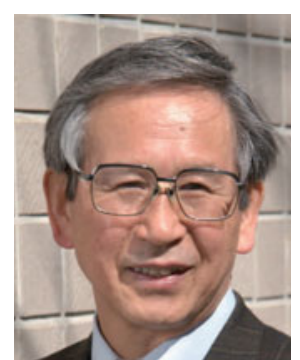

Masatake Haruta received PhD from Kyoto University in 1976, when he was offered a researcher position at ONRI. In 2001, he moved to Tsukuba as the director of the Research Institute for Green Technology, AIST. In 2005, he was appointed as a professor at Tokyo Metropolitan University.

\section{References}

1 M. Haruta, Chem. Rec. 2003, 3, 75-87

2 T. Ishida, M. Haruta, Angew. Chem. Int. Ed. 2007, 46, 7154-7156

3 H. Miyamura, R. Matsubara, Y. Miyazaki, S. Kobayashi, Angew. Chem. Int. Ed. 2007, 46, 4151-4154

4 S. Kanaoka, N. Yagi, Y. Fukuyama, S. Aoshima, H. Tsunoyama, T. Tsukuda, H. Sakurai, J. Am. Chem. Soc. 2007, 129, 12060-12061

5 A. Biffis, S. Cunial, P. Spontoni, L. Prati, J. Catal. 2007, 251, 1-6

6 T. Ishida, S. Okamoto, R. Makiyama, M. Haruta, Appl. Catal. A: Gen. 2009, 353, 243-248

7 S. Hermes, M.K. Schröter, R. Schmid, L. Khodeir, M. Muhler, A. Tissler, R.W. Fischer, R.A. Fischer, Angew. Chem. Int. Ed. 2005, 44, 6237-6241

8 M. Sabo, A. Henschel, H. Fröde, E. Klemm, S. Kaskel, J. Mater. Chem. 2007, 17, 3827-3832

9 F. Schröder, D. Esken, M. Cokoja, M.W.E. van den Berg, O.I. Lebedev, G. Van Tendeloo, B. Walaszek, G. Buntkowsky, H.H. Limbach, B. Chaudret, R.A. Fischer, J. Am. Chem. Soc. 2008, 130, 6119-6130

10 T. Ishida, M. Nagaoka, T. Akita, M. Haruta, Chem. Eur. J. 2008, 14, 8456-8460

11 H.L. Jiang, B. Liu, T. Akita, M. Haruta, H. Sakurai, Q. Xu, J. Am. Chem. Soc. 2009, 131, 11302-11303
12 A Grirrane, A. Corma, H. García, J. Catal. 2009, 264 138-144

13 H. Sun, F.Z. Su, J. Ni, Y. Cao, H.Y. He, K.N. Fan, Angew. Chem. Int. Ed. 2009, 48, 4390-4393

14 N.A. Ramsahye, G. Maurin, S. Bourrelly, P. Llewellyn, T. Loiseau, G. Férey, Phys. Chem. Chem. Phys. 2007, 9, 1059-1063

15 H.Li, M. Eddaoudi, M. O’Keeffe, O.M. Yaghi, Nature 1999, 402, 276-279

16 M. Kondo, T. Okubo, A. Asami, S.I. Noro, T. Yoshitomi, S. Kitagawa, Angew. Chem. Int. Ed. 1999, 38, 140-143

17 S. Tsubota, M. Haruta, T. Kobayashi, A. Ueda, Y. Nakahara, Stud. Surf. Sci. Catal. 1991, 63, 695-704

18 B. Zhu, M. Lazar, B.G. Trewyn, R.J. Angelici, J. Catal. 2008, 260, 1-6

19 A. Grirrane, A. Corma, H. García, Science 2008, 322, 1661-1664

20 E. Bus, J.T. Miller, J.A. Van Bokhoven, J. Phys. Chem. B 2005, 109, 14581-14587

21 A. Abad, A. Corma, H. García, Chem. Eur. J. 2008, 14, 212-222

22 P. Fristrup, L.B. Johansen, C.H. Christensen, Chem. Commun. 2008, 2750-2752

23 M. Conte, H. Miyamura, S. Kobayashi, V. Chechik, J. Am. Chem. Soc. 2009, 131, 7189-7196

24 F.Z. Su, L. He, J. Ni, Y. Cao, H.Y. He, K.N. Fan, Chem. Commun. 2008, 3531-3533

25 L.L. Santos, P. Serna, A. Corma, Chem. Eur. J. 2009, 15, 8196-8203

26 Shimizu et al. have very recently reported the $N$-alkylation of benzylalcohol over $\mathrm{Ag} / \mathrm{Al}_{2} \mathrm{O}_{3}$ and $\mathrm{Au} / \mathrm{Al}_{2} \mathrm{O}_{3}$ in the co-presence of $\mathrm{FeCl}_{3} \cdot 6 \mathrm{H}_{2} \mathrm{O}$. In this case, the aid of $\mathrm{FeCl}_{3}$ and $\mathrm{Al}_{2} \mathrm{O}_{3}$ are required to obtain secondary amine; $\mathrm{K}$.-I. Shimizu, M. Nishimura, A. Satsuma, ChemCatChem 2009, 1, 497-503 